\title{
Effects of peripheral sympathetic denervation induced by guanethidine administration on the mechanisms regulating puberty in the female guinea pig
}

\author{
L Riboni ${ }^{1}$, C Escamilla ${ }^{2}$, R Chavira ${ }^{3}$ and R Domínguez ${ }^{4}$ \\ ${ }^{1}$ Escuela de Biología and ${ }^{2}$ Bioterio Claude Bernard, Universidad Autónoma de Puebla, ${ }^{3}$ Departamento de Biología de la Reproducción, Instituto Nacional de la \\ Nutrición 'Salvador Zubirán' and 'Unidad de Investigación en Biología de la Reproducción, FES-Zaragoza, UNAM, Mexico \\ (Requests for offprints should be addressed to L Riboni, AP 574, Puebla, Pue, Mexico)
}

\begin{abstract}
The effects of peripheral sympathetic denervation induced by guanethidine administration to newborn and 10-dayold female guinea pigs on puberty, ovulation and the follicular population were analysed. Peripheral sympathetic denervation beginning at birth resulted in the loss of ovarian norepinephrine content $(0.95 . \pm 0 \cdot 1 \mathrm{ng} / \mathrm{mg}$ wet tissue in untreated control animals vs non detectable in treated animals). Guanethidine administration to newborn or 10-day-old guinea pigs advanced puberty (age of vaginal opening: $27 \pm 1 \cdot 2$ days (newborn), $26 \pm 1 \cdot 7$ (10day-old) vs $37 \pm 0.7$ (control), $P<0.001)$ and ovulation. The number of corpora lutea in control and denervated animals was similar $(3.5 \pm 0.2$ vs $3.3 \pm 0 \cdot 3)$. The relative weight $(\mathrm{mg} / 100 \mathrm{~g}$ body weight) of the ovaries and adrenals in the denervated animals autopsied during the late follicular phase (24-48 h after vaginal opening) increased (ovaries: $27 \cdot 8 \pm 1 \cdot 3,28 \cdot 9 \pm 3 \cdot 0$ vs $20 \cdot 9 \pm 0 \cdot 8$, $P<0 \cdot 05$; adrenals $36 \cdot 4 \pm 1 \cdot 4,37 \cdot 0 \pm 0 \cdot 8$ vs $31 \cdot 6 \pm 1 \cdot 5$, $P<0 \cdot 05)$, while the uterine weight diminished $(179 \pm 13$, $149 \pm 28$ vs $292 \pm 20$ ). When the animals were killed during the late luteal phase (9-11 days after vaginal closure), the relative weight of the ovaries of newborn guanethidine-treated animals was higher than that of the control animals $(21 \cdot 4 \pm 1 \cdot 7$ vs $16 \cdot 8 \pm 1 \cdot 4, P<0 \cdot 05)$. The
\end{abstract}

mean number of follicles counted in the ovaries of denervated animals was significantly higher than in control animals $(1736 \pm 230$ vs $969 \pm 147, P<0 \cdot 05)$. The mean diameter of the follicles in the untouched control ovary in animals killed in the late follicular phase was significantly larger than from animals killed in the late luteal phase $(263 \pm 3.9 \mu \mathrm{m}$ vs $248 \pm 3.0 \mu \mathrm{m}, P<0 \cdot 01)$. The mean diameter of the follicles measured in the ovaries of denervated animals was significantly higher than in controls (animals treated from birth $274 \pm 2 \cdot 0 \mu \mathrm{m}$ vs $255 \pm 2 \cdot 4, \quad P<0 \cdot 05 ;$ animals treated from day 10 , $286 \pm 2 \cdot 3 \mu \mathrm{m}$ vs $257 \pm 2 \cdot 3, P<0 \cdot 05)$. When the mean diameter of the follicles in the left and right ovary of the untouched control was analysed, the follicular diameter in the left ovary was significantly larger than in the right ovary ( $309 \pm 6 \cdot 0 \mu \mathrm{m}$ vs $214 \pm 3 \cdot 9, P<0 \cdot 01)$; the response of the left and right ovaries to sympathetic denervation was the opposite. The results obtained in the present study suggest that ovarian innervation plays a role in the regulation of follicular growth, maturation and atresia which is not related to changes in steroid secretion by the ovary, but to other regulatory mechanisms.

Journal of Endocrinology (1998) 156, 91-98

\section{Introduction}

The participation of peripheral ovarian innervation in the regulation of ovarian functions in the adult and prepubertal animal is a controversial issue. According to Lara et al. (1990) and Flores et al. (1990), sympathetic chemical denervation induced by guanethidine administration to 7-day-old or newborn rats, results in a delay of puberty. Pharmacological administration of guanethidine in adults has demonstrated that it is a specific noradrenergic blocker which does not cross the haematoencephalic barrier (Oates 1995). Its administration to rats results in the destruction only of postganglionic sympathetic neurones (Johnson \&
Manning 1984). The effects of guanethidine in rats has been explained by its actions as a false neurotransmitter (Boullin et al. 1966) and/or by neuronal destruction which involves a drug-induced, apparently cell-mediated, autoimmune attack on the sympathetic neurone (Manning et al. 1983). According to Johnson and Manning (1984), the immune response elicited by guanethidine administration resulting in the destruction of sympathetic neurones, is true only in rats. Based on the number of sympathetic neurones surviving after chronic guanethidine treatment, the sensitivity of the rat varies with the strain used.

According to Donovan (1990) 'the hormones physiologically active in controlling the onset of puberty in the 
guinea pig still await identification'. It has been postulated that a major neuroendocrine change occurs in the female guinea pig between 10-15 days of age (Nass et al. 1984a). Then, ovarian steroids can stimulate luteinizing hormone (LH) release in the immature female guinea pig, but not until an age is reached near the normal time of the first ovulation (Nass et al. 1984b). The presence of antral follicles has been described in the ovaries of newborn guinea pigs (Peddie 1976). On days 7 to 28 of life, the number of antral follicles increases, in spite of folliclestimulating hormone (FSH) and $\mathrm{LH}$ serum concentrations declining since birth and increasing only just before puberty at about 45 days of age (Donovan et al. 1975a,b).

We have shown previously that gonadotrophin or oestradiol administration to newborn female guinea pigs resulted in precocious puberty (D'Albora et al. 1974, Medero \& Domínguez 1977).

By analysing the effects of sympathetic denervation induced by guanethidine administration to rats (Domínguez \& Zipitría 1980, Flores et al. 1990) and mice (Rosas et al. 1989), we have proposed that ovarian noradrenergic innervation plays a stimulatory role on the control of ovulation in adult rats, while during the prepubertal period its role is inhibitory (Flores et al. 1990).

Because guinea pig ovaries have a dense noradrenergic innervation, and because it has been suggested that nerves may exert a trophic influence on follicular development (Burden 1972), the goal of this study was to analyse the participation of sympathetic ovarian innervation in the prepubertal female guinea pig on the regulation of puberty. This was achieved by studying the effects of guanethidine treatment in newborn and prepubertal female guinea pigs on spontaneous ovulation and hormonal secretion. According to Johnson and Manning (1984), 'destruction of the sympathetic nervous system produced by chronic treatment with high doses of guanethidine has been observed only in the rat'. Treatment of adult guinea pigs $(30 \mathrm{mg} / \mathrm{kg} /$ day guanethidine, intraperitoneally) for six weeks does not result in the destruction of sympathetic neurones (O’Donnell \& Saar 1974).

\section{Materials and Methods}

Fifty-seven female guinea-pigs were used. They were from the Hartley strain and were maintained in an artificially controlled lighted room (lights on from 0600 to $1900 \mathrm{~h}$ ), with laboratory chow, alfalfa and water available ad libitum.

The animals were weaned at 10 days of age, and were observed for vaginal opening daily thereafter. Puberty is defined as the age of first vaginal opening (Carlevaro et al. 1969). In the adult female guinea pig, the oestrous cycle lasts $16-20$ days, for $13-15$ days of which the vagina is closed with a membrane (vaginal closure period). This membrane is lost for a period of 3-6 days (vaginal opening period). The vaginal closure period corresponds to dioestrus and is characterised by high plasma levels of progesterone and FSH, and low plasma levels of oestradiol and $\mathrm{LH}$, compared with the pro-oestrous-oestrous period (Croix \& Franchimont 1975). The pro-oestrous-oestrous (pre- and postovulatory) period starts with the rupture of the vaginal membrane (vaginal opening) which lasts 3 to 6 days. During this period, an abrupt increase in FSH and oestradiol, followed by a peak in LH plasma levels has been described (Croix \& Franchimont 1975). In our strain, the ability of the female to mate (behavioural oestrus), begins during the second day after vaginal opening. Based on these events, the time of autopsy was defined as the late follicular phase (24-48 $\mathrm{h}$ after vaginal opening) or as the late luteal phase (9-11 days after vaginal closure) (Buño et al. 1975).

Animals were allocated randomly to one of the following groups: (1) twenty-two females were used as an untouched control group. Sixteen were killed in the late follicular phase and six in the late luteal phase. (2) Twenty-six animals were injected subcutaneously (s.c.) with guanethidine sulphate (Sigma Chemical Company, St Louis, MO, USA) in saline ( $20 \mathrm{mg} / \mathrm{kg}$, twice a week) beginning on the day of birth. Such a dose is similar to those used in humans for blood hypertension treatment (Oates 1995). Twelve animals were killed in the late follicular phase and fourteen in the late luteal phase. To analyse whether such a dose of guanethidine depletes noradrenaline completely from the ovaries, as has been shown for rats, three newborn guinea pigs were injected with guanethidine $(20 \mathrm{mg} / \mathrm{kg})$ twice a week, three doses distributed over 9 days, and four animals of the same age without treatment were used as controls. The animals were killed $24 \mathrm{~h}$ after the last injection of guanethidine. The ovaries were dissected, weighed and norepinephrine content was measured by high performance liquid chromatography (HPLC), following the procedure previously described (Chávez et al. 1994). The destruction produced by guanethidine in neonates is more rapid and more complete than in adult animals (Johnson \& Manning 1984). (3) Twenty-three animals were injected (s.c.) with guanethidine $(20 \mathrm{mg} / \mathrm{kg}$, twice a week) beginning on day 10 of life. Seventeen were killed in the late follicular phase and six in the late luteal phase.

\section{Autopsy procedure}

The animals were killed by bleeding under ether anaesthesia. The blood was allowed to clot and centrifuged at 3000 r.p.m.. The serum was stored at $-20^{\circ} \mathrm{C}$ until oestradiol and progesterone were measured in duplicate by specific radioimmunoassays following the methodology of Orczyk et al. (1974), using reagents and protocols provided by the Matched Reagent Programme of the Special Programme of Research, Development and Training in Human Reproduction of the World Health Organization 
Table 1 Body weight and relative weight (mg/100 g body weight) of the ovaries, uterus and adrenals in female guinea pig, controls and animals treated with guanethidine (GTD) $(20 \mathrm{mg} / \mathrm{kg})$ at birth or on day 10 of life and killed in the late follicular or the late luteal phase. Values are means \pm S.E.M.

\begin{tabular}{|c|c|c|c|c|}
\hline & $\begin{array}{l}\text { Body weight } \\
\text { (g) }\end{array}$ & $\begin{array}{l}\text { Ovaries } \\
(\mathrm{mg} / 100 \mathrm{~g})\end{array}$ & $\begin{array}{l}\text { Uterus } \\
(\mathrm{mg} / 100 \mathrm{~g})\end{array}$ & $\begin{array}{l}\text { Adrenals } \\
(\mathrm{mg} / 100 \mathrm{~g})\end{array}$ \\
\hline \multicolumn{5}{|l|}{ Group } \\
\hline \multicolumn{5}{|c|}{ Late follicular phase } \\
\hline Control & $327 \pm 6 \cdot 0$ & $20 \cdot 9 \pm 0 \cdot 8$ & $292 \pm 20$ & $31 \cdot 6 \pm 1 \cdot 5$ \\
\hline GTD birth & $261 \pm 8 \cdot 5^{*}$ & $27 \cdot 8 \pm 1 \cdot 3^{*}$ & $179 \pm 13^{*}$ & $36 \cdot 4 \pm 1 \cdot 4^{*}$ \\
\hline GTD 10 & $248 \pm 16^{*}$ & $28 \cdot 9 \pm 3 \cdot 0^{*}$ & $149 \pm 28^{*}$ & $37 \cdot 0 \pm 0 \cdot 8^{*}$ \\
\hline \multicolumn{5}{|c|}{ Late luteal phase } \\
\hline Control & $448 \pm 12 \cdot 5$ & $16 \cdot 8 \pm 1 \cdot 4$ & $242 \pm 33$ & $35 \cdot 4 \pm 2 \cdot 2$ \\
\hline GTD birth & $405 \pm 13 \cdot 8$ & $21 \cdot 4 \pm 1 \cdot 7^{*}$ & $199 \pm 24$ & $40 \cdot 3 \pm 2 \cdot 0$ \\
\hline GTD 10 & $421 \pm 6 \cdot 1$ & $20 \cdot 6 \pm 1 \cdot 7$ & $195 \pm 14$ & $39 \cdot 5 \pm 1 \cdot 8$ \\
\hline
\end{tabular}

(Geneva, Switzerland). The endocrine organs (ovaries, uterus and adrenals) were dissected and weighed on a precision balance. The ovaries were fixed in Bouin's fluid, embedded in paraffin wax, serially sectioned at $10 \mu \mathrm{m}$ and stained with haematoxylin and eosin. The presence of fresh corpora lutea was accepted as evidence of previous ovulation.

\section{Morphometric analysis of the follicular distribution}

All the follicles present in each $100 \mu \mathrm{m}$ section were measured with the aid of an ocular micrometer, following Weibel's (1979) methodology. In brief, all follicles contained in the test area were measured, taking care that the follicles with a diameter larger than $450 \mu \mathrm{m}$ were measured only once. The follicles were classified as healthy or atretic based on the following characteristics: a follicle was considered atretic when either the oocytes showed obvious signs of degeneration or granulosa cells were present in the follicular antrum (Cruz \& Domínguez 1992).

Data on the weight of endocrine organs, expressed as $\mathrm{mg} / 100 \mathrm{~g}$ body weight, norepinephrine, oestradiol and progesterone concentrations, and the mean follicular diameter were analysed using variance analysis (ANOVA) followed by Tukey's test or by Student's $t$-test. Ovulation rate, expressed as the number of animals with corpora lutea in the ovaries/number of treated animals, was analysed by Fisher's exact probability test. The results of the follicular distribution were analysed using a Chi square test. A probability less than $5 \%$ was considered as significant.

\section{Results}

The body weights of control animals killed in the late luteal phase were significantly higher than those killed in the late follicular phase. The relative weight $(\mathrm{mg} / 100 \mathrm{~g}$ body weight) of the ovaries was higher in control animals killed in the late follicular phase than those killed in the late luteal phase (Table 1).

The ovarian norepinephrine concentration of intact control animals was $0 \cdot 95 \pm 0 \cdot 1 \mathrm{ng} / \mathrm{mg}$ wet tissue, while in guanethidine-treated animals it was below the detection limit of the method $(50 \mathrm{pg})$.

The age of vaginal opening in animals denervated at birth or on day 10 of life was significantly advanced (treated at birth, $27 \pm 1 \cdot 2$ days; treated on day 10, $26 \pm 1 \cdot 7$ vs control, $37 \pm 0 \cdot 7 ; P<0 \cdot 001$, ANOVA followed by Tukey's test). In guanethidine (GTD)-treated animals killed in the late follicular phase, the weight of the ovaries and adrenals was higher than in the controls, while the weight of the uterus was significantly lower. When the animals were killed in the late luteal phase, the weight of the ovaries was significantly higher in the newborn denervated female than in the female controls. No differences in the weights of the uterus and adrenals were observed (Table 1).

The histological analysis of the ovaries of all animals, control and guanethidine-treated, killed in the late luteal phase showed the presence of corpora lutea, but none were present in the ovaries of the animals killed in the late follicular phase. The number of corpora lutea present in the ovaries in control and denervated animals was similar (control, $3.3 \pm 0.3$ vs guanethidine-treated, $3.5 \pm 0 \cdot 2$, Mann-Whitney U test).

The serum oestrogen concentrations in newborn or 10-day-old guanethidine-denervated animals killed in the late follicular phase were similar to the levels measured in control animals (78.4 \pm 6.7 (newborn); $82.33 \pm 7 \cdot 8$ (10day-old) vs $94 \cdot 39 \pm 5 \cdot 0$ (control) $\mathrm{pg} / \mathrm{ml}$ ), while the serum progesterone concentrations were significantly higher $(1.97 \pm 0 \cdot 4 ; \quad 1.47 \pm 0.2$ vs $0.33 \pm 0.2 \mathrm{ng} / \mathrm{ml} ; \quad P<0.01$, Student's $t$-test). When the animals were killed in the late 


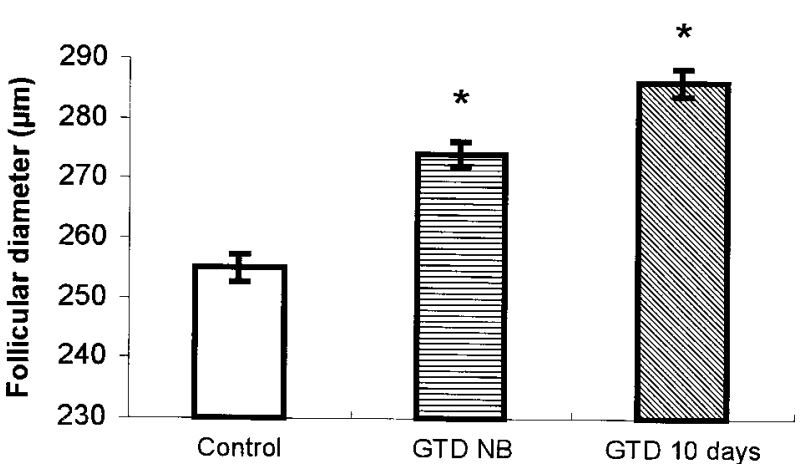

Figure 1 Follicular diameter $(\mu \mathrm{m})$ measured in the ovaries of control and newborn (GTD NB) or 10-day-old (GTD 10 days) denervated guinea pigs. Values are means \pm S.E.M. ${ }^{*} P<0 \cdot 05$ compared with control group (ANOVA followed by Tukey's test).

luteal phase, the serum oestrogen concentrations in animals denervated from birth were higher than in controls $(147 \cdot 52 \pm 10 \cdot 5$ vs $86 \cdot 79 \pm 9 \cdot 8 \mathrm{pg} / \mathrm{ml} ; P<0 \cdot 05$, Student's $t$-test), while when the administration of guanethidine began on day 10 , significant differences compared with the controls were not observed $(75 \cdot 80 \pm 12 \cdot 3$ vs $86.93 \pm$ $9 \cdot 8 \mathrm{pg} / \mathrm{ml})$. All denervated animals killed during the late luteal phase had lower serum progesterone levels than in the controls $(0.59 \pm 0 \cdot 1 ; 0.76 \pm 0.4$ vs $1.63 \pm 0.4 \mathrm{ng} / \mathrm{ml}$; $P<0 \cdot 02$, ANOVA followed by Tukey's test).

The mean number of follicles counted in the ovaries of denervated guinea pigs was significantly higher than in control animals $(1736 \pm 230$ vs $969 \pm 147 ; P<0 \cdot 05$, Mann-Whitney U test). The mean diameter of the follicles in the untouched control ovary of animals killed in the late follicular phase was significantly larger than those killed in the late luteal phase $(263 \pm 3 \cdot 9$ vs $248 \pm 3 \cdot 0 \mu \mathrm{m} ; P<0 \cdot 01$, Student's $t$-test).

The total and relative (percentage) number of follicles with diameters larger than $600 \mu \mathrm{m}$ measured in the ovaries of guanethidine-treated animals was significantly higher than in controls (late follicular phase, $3 \cdot 17 \%$ vs $1.86 \%$; late luteal phase, $3 \cdot 78 \%$ vs $1 \cdot 65 \% ; P<0 \cdot 05$, Chi square test). In these follicles, the incidence of atresia was also higher in denervated animals (late follicular phase, $3 \cdot 12 \%$ vs $1 \cdot 15 \%$; late luteal phase, $3 \cdot 02 \%$ vs $1.91 \% ; P<0 \cdot 05$, Chi square test).

The mean diameter of the follicles measured in the ovaries of denervated animals was significantly larger than in controls (Fig. 1). When the results were analysed according to the phase of the oestrous cycle when the animals were killed, such differences were significant only in those animals killed in the late luteal phase (Fig. 2).

The follicular diameter in healthy and atretic follicles in those animals killed in the late follicular or the late luteal phase, was affected by sympathetic denervation in a different way. The mean diameter of the healthy follicles of guanethidine-treated guinea pigs, killed in the late

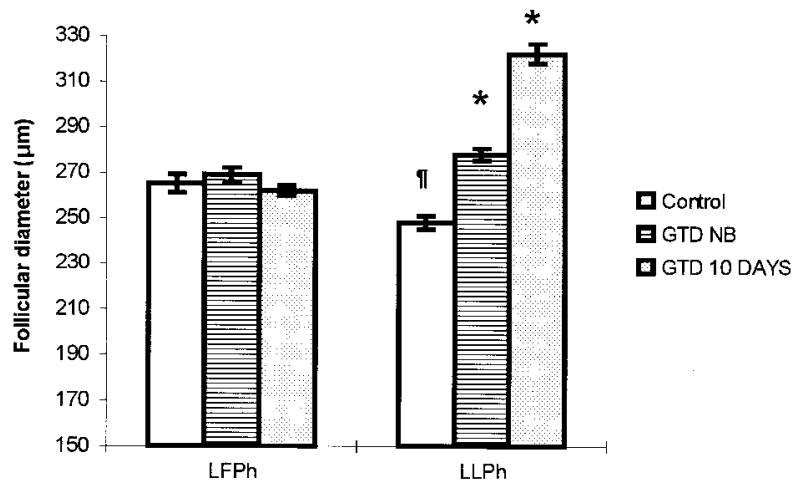

Figure 2 Follicular diameter $(\mu \mathrm{m})$ measured in the ovaries of control and newborn (GTD NB) or 10-day-old (GTD 10 days) denervated guinea pigs killed during the late follicular phase (LFPh) or the late luteal phase (LLPh). Values are means \pm S.E.M. ${ }^{*} P<0 \cdot 01$ compared with control group; $\mathbb{\Psi} P<0 \cdot 01$ compared with LFPh (ANOVA followed by Tukey's test).
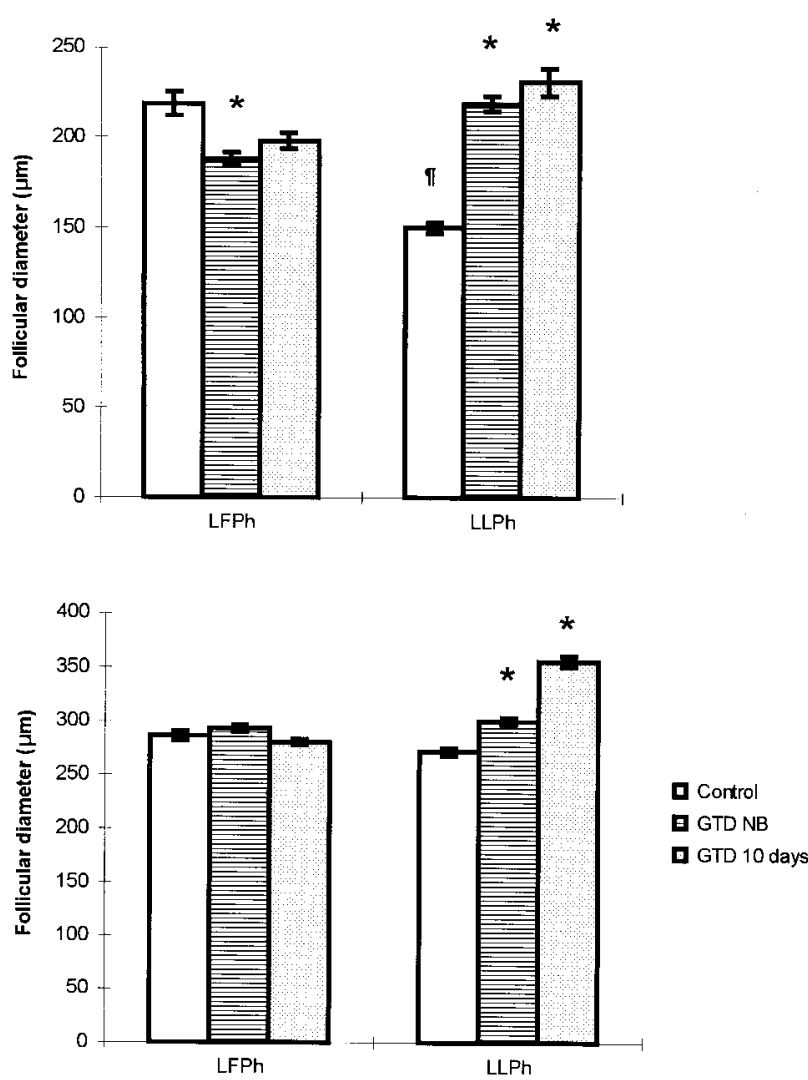

Figure 3 Follicular diameter $(\mu \mathrm{m})$ measured in the ovaries of control, newborn (GTD NB) and 10-day-old (GTD 10 days) guinea pigs treated with guanethidine and killed in the late follicular phase (LFPh) or the late luteal phase (LLPh). Upper panel: healthy follicles; lower panel: atretic follicles. Values are means \pm S.E.M. ${ }^{*} P<0.01$ compared with proper control; $₫ P<0.01$ compared with left control ovary (ANOVA followed by Tukey's test). 

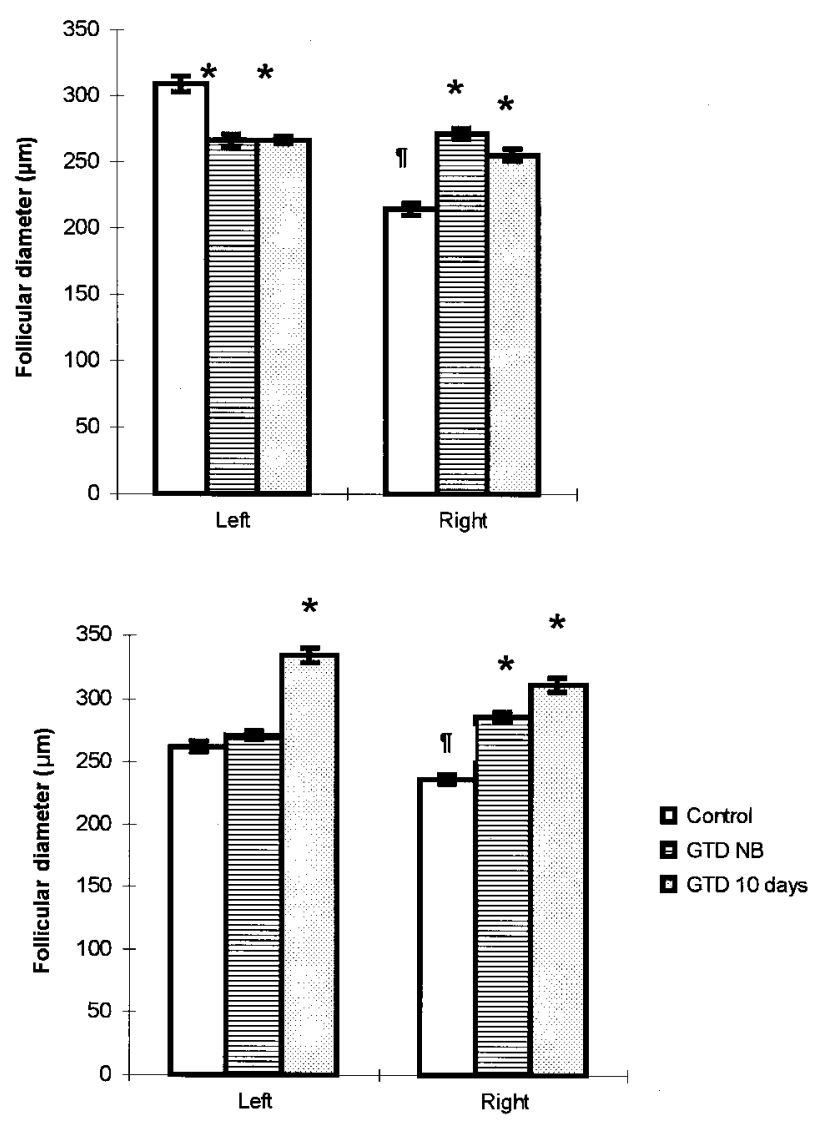

Figure 4 Follicular diameter $(\mu \mathrm{m})$ of the left and right ovaries of control, newborn (GTD NB) and 10-day-old (GTD 10 days) guinea pigs killed in the late follicular phase (LFPh; upper panel) or the late luteal phase (LLPh; lower panel). Values are means \pm S.E.M. ${ }^{*} P<0.01$ compared with proper control; $\mathbb{\Psi} P<0.01$ compared with left control ovary (ANOVA followed by Tukey's test).

follicular phase, was significantly smaller than in controls. When the animals were killed in the late luteal phase, the mean diameter of the healthy follicles of the ovaries of denervated animals was significantly larger than in control animals (Fig. 3, upper panel). Differences in the mean follicular diameter of the atretic follicles of denervated and control guinea pigs killed in the late follicular phase were not observed. When the animals were killed during the late luteal phase, the mean diameter of the atretic follicles in the ovaries of denervated animals was significantly larger than in control animals (Fig. 3, lower panel).

When the mean diameter of the follicles in the left and right ovaries of the control animals was analysed, the follicular diameter in the left ovary was significantly greater than in the right ovary. The response of the left and right ovaries to noradrenergic denervation was the opposite: in the left ovary, the follicular diameter was smaller than controls, whereas in the right ovary the diameter of the denervated ovary was always greater than in controls (Fig. 4).

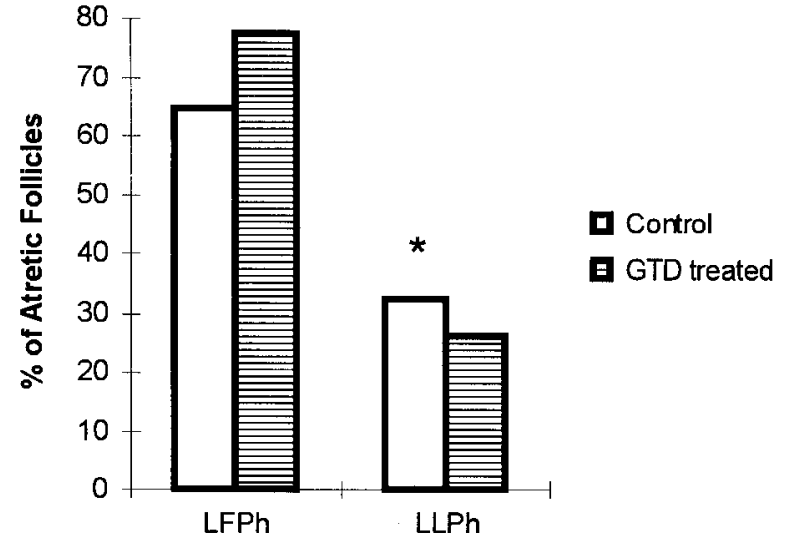

Figure 5 Percentage of atretic follicles measured in the ovaries of control and guanethidine (GTD)-treated guinea pigs killed during the late follicular phase (LFPh) or the late luteal phase (LLPh). ${ }^{*} P<0.05$ compared with control group (ANOVA followed by Tukey's test).

The percentage of atretic follicles measured in the ovaries of control and guanethidine-treated guinea pigs killed during the late follicular phase was higher than for those killed in the late luteal phase (Fig. 5). Significant differences in the incidence of atresia between control and denervated animals were not observed; however, the number of atretic follicles was always higher in denervated compared with control guinea pigs.

\section{Discussion}

In addition to the general effects resulting from the sympathetic-peripheral denervation induced by guanethidine administration, the present results agree with the notion that in prepubertal females, ovarian-sympathetic (noradrenergic?) innervation plays an inhibitory, modulatory role in the reactivity of the ovaries to endogenous gonadotrophins (Flores et al. 1990). The possibility that peripheral denervation induced by guanethidine results in an alteration of blood pressure seems unlikely since such treatment in humans produces orthostatic hypotension, which is readily compensated (Oates 1995).

Both Flores et al. (1990), who administered $20 \mathrm{mg} / \mathrm{kg}$ guanethidine sulphate to newborn rats and Lara et al. (1990) who used $50 \mathrm{mg} / \mathrm{kg}$ guanethidine monosulphate, observed a delay in puberty. The differences observed in the results in guanethidine-treated rats (Flores et al. 1990, Lara et al. 1990) and guinea pigs (present results) appear to reflect the differences in the amount of noradrenergic innervation in the two species (Burden 1972). There is evidence that chronic guanethidine treatment of adult guinea pig, adult and newborn cats, adult mice, adult toads, rabbits, hamsters, gerbils and chickens does not result in neuronal death (Johnson \& Manning 1984). 
Another possibility is that guanethidine administration results in an alteration of ovarian sensory nerve fibres. In long-term guanethidine-treated rats, an increase in the number of fibres expressing the neuropeptide calcitonin gene-related peptide (CGRP) has been described (Aberdeen et al. 1990, Mione et al. 1992). In the periphery, CGRP has been implicated mainly in sensory functions and, in particular, in pain transmission (Mione et al. 1992).

To our knowledge, there is no information on the kind of information conveyed by the ovarian sensory nerve fibres. If such fibres exist in the guinea pig ovary, based on the increased mean number and diameter of antral follicles, we could postulate that such innervation sends information about the secretion of substances such as activin affecting FSH secretion by the pituitary. In addition, the 'partial' sympathetic denervation would result in hypersensitivity of the follicles to gonadotrophins.

Age progression of vaginal opening reflects early oestrogen secretion by the ovary. Such a view is supported by the similarity in the serum oestrogen levels observed in guanethidine-denervated animals and in controls, (denervated animals appeared 10 days more advanced than controls). It is generally accepted that the largest healthy follicles produce higher amounts of oestrogen (Greenwald \& Roy 1994). Since the number of follicles with a diameter greater than $600 \mu \mathrm{m}$ in the ovaries of denervated guinea pigs autopsied in the late follicular phase was higher than in control animals (16 vs 7 ), we suggest that the number of units producing oestrogen was increased, which resulted in the advancement of vaginal opening. An increase in the sensitivity of the denervated vagina to oestrogen cannot, however, be discounted.

The increased serum progesterone level in denervated animals compared with controls cannot be explained by differences in luteal function, because none of the animals, whether denervated or control, had corpora lutea in their ovaries. Studies in vitro using ovarian thecal interstitial cells showed that the addition of norepinephrine, epinephrine or isoproterenol to the medium enhanced androgen production in response to human chorionic gonadotrophin (hCG) (Dyer \& Erickson 1985). This sympathetic alteration in ovarian innervation induced by guanethidine treatment would result in the accumulation of progesterone, while an active aromatase would convert any androgens which are present to oestrogen, resulting in the normal serum levels observed. Another possibility is that guanethidine administration results in changes in the ovarian content of neuropeptide $\mathrm{Y}$ and substance $\mathrm{P}$. There is evidence that both peptides stimulate in vitro ovarian progesterone secretion (Pitzel et al. 1991). There is controversial evidence of the effects of guanethidine on substance $\mathrm{P}$ fibre content. Changes in the number of substance $\mathrm{P}$ fibres in guanethidine-treated rats were not observed by Aberdeen et al. (1990), while a significant increase of such fibres has been described by Mione $e t$ al.
(1992). Because the weight of the adrenals was higher in denervated guinea pigs than in controls, we can suppose that the progesterone measured in denervated animals is of adrenal origin.

The advanced ovulation observed in noradrenergicdenervated animals (true puberty), would agree with Ross's (1990) statement that 'the steroid hormones mediate some of the effects of gonadotrophins on preovulatory growth and differentiation, because oestrogen induces the LH receptors (Richards 1979) and aromatase activity in granulosa cells (Daniel \& Armstrong 1983)'. The high serum oestrogen level observed in newborn denervated animals killed in the late luteal phase can be explained by the increased number of healthy follicles observed in the ovaries of these animals (812 vs 416). Such an increase was not observed in those animals treated with guanethidine beginning on day 10 of life, and is in agreement with the fact that the number of healthy follicles was similar to control animals (436 vs 416). The low progesterone levels measured in the serum of all denervated guinea pigs killed during the late luteal phase suggest that noradrenergic ovarian innervation plays a stimulatory role in the control of corpora lutea function.

The higher incidence of atresia in larger follicles (diameter $>600 \mu \mathrm{m}$ ) in denervated animals than in controls cannot be explained by endocrine modifications. There is evidence that (1) norepinephrine acts synergistically with $\mathrm{LH} / \mathrm{hCG}$ on the stimulation of androgen secretion (Dyer \& Erickson 1985), (2) in the peripubertal stage of the rat, the number of $\beta 2$-adrenergic receptors is very high and their stimulation results in an increase in testosterone output (Aguado et al. 1982), (3) ovarian denervation produced a decrease in the $\Delta 5-3 \beta-$ hydroxysteroid dehydrogenase activity in the rat ovary during pregnancy (Burden \& Lawrence 1977), and (4) in accordance with Greenwald and Roy (1994), the steroid profiles in atretic follicles demonstrate a fall in oestrogen secretion, attributable to a shutdown in thecal androgen secretion. Therefore, the increase in the number of atretic follicles in the ovaries of guanethidine-denervated guinea pigs reflects the modification of other mechanisms regulating the atresia of the follicles related, perhaps, to thecal vascularity (Greenwald 1993).

According to Mills and Reed (1971) there exists a 'crucial period' just before first oestrus for the ovary of guinea pigs to ovulate in response to exogenous gonadotrophins. At this time ovulation can be induced by gonadotrophin administration, while 'immature controls' treated with four daily injections of ovine FSH did not show signs of oestrogen secretion (vaginal opening did not occur) or ovulation $24 \mathrm{~h}$ after the last injection. Such an idea was not supported by the studies of Curry et al. (1984) and Riboni et al. (1995), who have shown that the sequential administration of pregnant mare's serum gonadotrophin (PMSG) followed by hCG to 25- or 10 -day-old guinea pigs, resulted in the advancement of 
ovulation as measured by the presence of fresh corpora lutea in the ovaries.

The increase in the adrenal weight of guanethidinetreated animals suggests that noradrenergic peripheral innervation plays a role in the regulation of the response of this tissue to other endocrine organs besides the ovaries.

There is some evidence that the right and left ovary respond differently. Differences in the ovulatory ability between the right and left ovary have been described in the human (Potashnik et al. 1987), pig (Hunter et al. 1985) and monkey (Morse \& Van Wagenen 1936). In the rat, such differences are related to the number of ova shed by the right and left ovary, the compensatory ovarian hypertrophy following hemiovariectomy, and its dependence on ovarian innervation (Ayala \& Domínguez 1988), in spite of the fact that the concentration of noradrenaline in the right and left ovaries is similar (Chávez et al. 1994). The differences in the number of follicles and mean diameter measured in the right and left ovary and the opposite response to peripheral denervation by healthy and atretic follicles could be related and would reflect differences in the neural information reaching each ovary.

The results obtained in this study suggest that ovarian innervation plays a role in the regulation of follicular growth, maturation and atresia which is not related to changes in steroid secretion by the ovary but to other regulatory mechanisms, for example, follicular vascularization (Greenwald 1993). Because such regulatory mechanisms present some asymmetry between the left and right ovary, it is possible that the neural information arises from a lateralised portion of the central nervous system, as has been shown previously in the rat (Cruz et al. 1990, Domínguez-González \& Chávez 1993, Ayala et al. 1994).

\section{Acknowledgements}

This work was supported by CONACYT, grant 2343P-M, PUIS, DGAPA, grant 210893 and PADEP, grant 500307.

\section{References}

Aberdeen J, Corr L, Milner P, Lincoln J \& Burnstock G 1990 Marked increases in calcitonin gene-related peptide-containing nerves in the developing rat following long-term sympathectomy with guanethidine. Neuroscience 35 175-184.

Aguado LI, Petrovic SL \& Ojeda SR 1982 Ovarian $\beta$-adrenergic receptors during the onset of puberty: characterization, distribution and coupling to steroidogenic responses. Endocrinology 110 $1124-1132$

Ayala ME \& Domínguez R 1988 Ovulatory response to the sequential administration of follicle stimulating hormone and human chorionic gonadotrophin by autografted ovary in unilaterally ovariectomized adult rat with peripheral denervation by guanethidine treatment. La Revista de Investigacion Clinica Mexico 40 149-155.

Ayala ME, Rosas P \& Domínguez R 1994 Different effects of unilateral and bilateral lesions of the dorsal raphe nucleus on puberty and first ovulation. Brain Research Bulletin 40 149-155.
Boullin DJ, Costa E \& Brodie BB 1966 Discharge of tritium-labeled guanethidine by sympathetic nerve stimulation as evidence that guanethidine is a false transmitter. Life Sciences 5 803-808.

Buño W, Carlevaro E, Riboni L, D'Albora H, de los Reyes L, Zipitría D \& Domínguez R 1975 Hysterectomy of the newborn guinea pig, subsequent effects on the oestrous cycle and life span of the corpora lutea. Journal of Endocrinology 66 233-237.

Burden HW 1972 Adrenergic innervation in ovaries of the rat and guinea pig. Journal of Anatomy 133 455-462.

Burden HW \& Lawrence IE Jr 1977 Effects of denervation on the localization of $\Delta-3 \beta$-hydroxysteroid dehydrogenase activity in the rat ovary during pregnancy. Acta Anatomica 97 286-290.

Carlevaro E, D’Albora H, Riboni L, de los Reyes L, Domínguez R \& Buöo W 1969 Effects of hemispaying on guinea pigs injected with testosterone on the first day of life. Acta Physiologica Latinoamericana 19 315-323.

Chávez R, Morales L, González ME \& Domínguez R 1994 Ovarian norepinephrine content in prepubertal rats with superior ovarian nerve section: temporal studies. Medical Science Research 22 789-790.

Croix D \& Franchimont P 1975 Changes in the serum levels of the gonadotrophins, progesterone and estradiol during the estrous cycle of the guinea pig. Neuroendocrinology 19 1-11.

Cruz ME \& Domínguez R 1992 Modifications in the follicular compartment of the ovaries of adult rats with a unilateral lesion of the hypothalamus. Medical Science Research 20 939-941.

Cruz ME, Morán JL, Jaramillo LP \& Domínguez R 1990 Differential effects of a unilateral hypothalamic lesion on ovulation and compensatory ovarian hypertrophy in hemiovariectomized adult rats. Journal of Endocrinology 124 37-41.

Curry TE Jr, Lawrence IE \& Burden HW 1984 Ovarian sympathectomy in the guinea pig. II. Effects on follicular development during the prepubertal period and following exogenous gonadotropin stimulation. Cell and Tissue Research 236 593-596.

D’Albora H, Carlevaro E, Riboni L, de los Reyes L, Zipitría D \& Domínguez R 1974 Advanced puberty in female guinea pigs treated with human chorionic gonadotrophin (HCG) or testosterone enantate (ET) at birth. Hormone Research 5 344-350.

Daniel SAJ \& Armstrong DT 1983 Involvement of estrogens in the regulation of granulosa cell aromatase activity. Canadian Journal of Physiology and Pharmacology 61 507-511.

Domínguez R \& Zipitría D 1980 Longterm effects of guanethidine administration on the ovulatory response of the rat. IRCS Medical Science 8352.

Domínguez-González A \& Chávez R 1993 Asymmetric effects of unilateral lesions in the midbrain central gray matter on ovulation in the adult female rat. Medical Science Research 21 513-514.

Donovan BT 1990 Puberty in the guinea pig and rabbit. In Control of the Onset of Puberty, Ch 5, pp 143-155. Eds MM Grumbach, PC Sizonenko \& ML Auberts. Baltimore, USA: Williams \& Wilkins.

Donovan BT, ter Haar MB, Lockhart AN, Mackinnon PCB, Mattock JM \& Peddie MJ 1975a Changes in the concentration of luteinizing hormone in plasma during development in the guinea-pig. Journal of Endocrinology 64 511-520.

Donovan BT, ter Haar MB, Lockhart AN \& Peddie MJ $1975 b$ Changes in the concentration of follicle-stimulating hormone in plasma during development in the guinea-pig. Journal of Endocrinology 64 521-528.

Dyer CA \& Erickson GF 1985 Norepinephrine amplifies human chorionic gonadotrophin-stimulated androgens biosynthesis by ovarian theca-interstitial cells. Endocrinology 16 1645-1652.

Flores A, Ayala ME \& Domínguez R 1990 Does noradrenergic peripheral innervation have a different role in the regulation of ovulation in pubertal and adult rat? Medical Science Research 18 817-818.

Greenwald GS 1993 How does daily treatment with hCG induce superovulation in the cyclic hamster? Biology of Reproduction $\mathbf{4 8}$ 133-142. 
Greenwald GS \& Roy SK 1994 Follicular development and its control. In The Physiology of Reproduction, ch 12, pp 629-724. Eds E Knobil \& JD Neil. New York: Raven Press Ltd.

Hunter RHF, Cook B \& Baker TG 1985 Intersexuality in five pigs, with particular reference to estrous cycle, the ovotestis, steroid hormone secretion and potential fertility. Journal of Endocrinology 106 233-242.

Johnson EM \& Manning PT 1984 Guanethidine-induced destruction of sympathetic neurones. International Review of Neurobiology 25 $1-37$.

Lara HE, McDonald JK, Ahmed CE \& Ojeda SR 1990 Guanethidinemediated destruction of ovarian sympathetic nerves disrupts ovarian development and function in rats. Endocrinology 127 2199-2209.

Manning PT, Powers CW, Schmidt RE \& Johnson Jr EM 1983 Guanethidine-induced destruction of peripheral sympathetic neurons occurs by an immune-mediated mechanism. The Journal of Neuroscience 4 714-724.

Medero M \& Domínguez R 1977 Induction of precocious puberty in newborn female guinea-pigs by a positive feedback action of estrogens. Hormone Research 8 224-230.

Mills PG \& Reed M 1971 The onset of first oestrus in the guinea-pig and the effects of gonadotrophins and oestradiol in the immature animal. Journal of Endocrinology 50 329-337.

Mione MC, Cavanagh JFR, Kirkpatrick KA \& Burnstock G 1992 Plasticity in expression of calcitonin gene-related peptide and substance $\mathrm{P}$ immunoreactivity in ganglia and fibres following guanethidine and/or capsaicin denervation. Cell and Tissue Research 268 491-504.

Morse AM \& Van Wagenen G 1936 Observations upon ovulation in primates. American Journal of Obstetrics and Gynecology 32 823-832.

Nass TE, Teresawa E, Dierschke DJ \& Goy RW 1984a Developmental changes in luteinizing hormone secretion in the female guinea pig. I. Effects of ovariectomy, estrogen, and luteinizing hormone releasing hormone. Endocrinology 115 220-226.

Nass TE, Teresawa E, Dierschke DJ \& Goy RW $1984 b$ Developmental changes in luteinizing hormone secretion in the female guinea pig. II. Positive feedback effects of ovarian steroids. Endocrinology 115 227-232.

Oates JA 1995 Antihypertensive agents and the drugs therapy of hypertension. In Goodman and Gilman: The Pharmacological Basis of
Therapeutics, edn 9, ch 33, pp 780-808. Eds in chief JG Hardman \& LE Limbird, Eds PB Molinoff \& RW Ruodon. USA: McGraw Hill.

O’Donnell R \& Saar N 1974 The effects of 6-hydroxydopamine and guanethidine on peripheral adrenergic nerves in the guinea pig. European Journal of Pharmacology 28 251-256.

Orczyck G, Caldwell BV \& Behrman 1974 Estrogens: estradiol, estrone and estriol. In Methods of Hormone Radioimmunoassay, ch 19, pp 333-358. Eds BM Jaffe \& HR Behrmann. New York, London: Academic Press.

Peddie MJ 1976 Ovarian follicular development in the immature guinea pig. Annales de Biologie Animale, Biochimie et Biophysique 16 313-314.

Pitzel L, Jarry J \& Wuttke W 1991 Effects of sustance-P and neuropeptide-Y on in vitro steroid release by porcine granulosa and luteal cells. Endocrinology 129 1059-1065.

Potashnik G, Insler V \& Meizner J 1987 Frequency, sequence, and side of ovulation in women menstruating normally. British Medical Journal 294219.

Riboni L, Escamilla C \& Domínguez R 1995 Advanced puberty in ovariectomized and hemiovariectomized female guinea pigs with ovarian autograft and treated with gonadotropins. Medical Science Research 23 307-308.

Richards JS 1979 Hormonal control of ovarian follicular development. Recent Progress in Hormone Research 35 343-368.

Rosas P, Argüello MS \& Domínguez R 1989 Effects of noradrenergic peripheral denervation on spontaneous or induced puberty in normal and hypothymic hairless female mice. Medical Science Research 17 285-286.

Ross GT 1990 Follicular development: the life cycle of the follicle and puberty. In Control of the Onset of Puberty, ch 17, pp 376-386. Eds MM Grumbach, PC Sizonenko \& ML Aubert. Baltimore, USA: Williams \& Wilkins.

Weibel ER 1979 Stereological Methods. Vol 1. Practical Methods for Biological Morphometry. London: Academic Press Inc.

Received 5 October 1995

Final version received 16 July 1997

Accepted 7 August 1997 